Elsevier required licence: (C2018. This manuscript version is made available under the CC-BY-NC-ND 4.0 license http://creativecommons.org/licenses/by-nc-nd/4.0/ 


\title{
Attenuating heat stress through green roof and green walls retrofit
}

\author{
Renato Castiglia Feitosa ${ }^{1}$, \& Sara J Wilkinson ${ }^{2}$ \\ ${ }^{1}$ Researcher at Oswaldo Cruz Foundation (Fiocruz) - Department of Sanitation and Environmental Health of \\ National School of Public Health, Rio de Janeiro - Brazil, rentcf@yahoo.com.br \\ ${ }^{2}$ School of Built Environment, Faculty of Design Architecture and Building UTS, Sydney - Australia, \\ sara.wilkinson@uts.edu.au
}

Keywords: Green roofs, Green walls, Heat index, Heat stress. 
Increased urbanisation has led to a worsening in the quality of life for many people in large cities, in respect of the urban heat island effect and increases of indoor temperatures in housing and other buildings. The total urban population is predicted to increase from 7.3 to 9.7 billion people by 2050 [1]. In terms of the concept of Urban Heat Islands (UHI), many suburban and urban areas experience elevated temperatures when compared to their outlying rural surroundings. The annual mean air temperature of a densely populated city can be between 1 to $3^{\circ} \mathrm{C}$ warmer than the surrounding areas, and on a clear, calm night, this temperature difference can reach $12^{\circ} \mathrm{C}$ [2]. As temperatures and populations increase, urban air quality worsens and the potential for increased health issues around heat stress grow, especially for older people. Despite rapid urbanisation and population growth, typically only $1-2 \%$ is added to the total stock of buildings annually, and therefore the focus for the maximum benefit for UHI mitigation lies with retrofitting existing buildings with vegetation applied to walls and roofs. These structures are known as green roofs and green walls. When building envelopes are covered with green roofs and green walls there is great potential to attenuate the UHI effect $[3,4,5,6,7]$. According to Herreira-Gomes [8] and Yaghoobian and Srebric [4] green roofs are an alternate way to mitigate climate change effects.

Compared to traditional roof surfaces typically covered with bitumen, asphalt or steel sheeting which are directly exposed to the sun, retrofitted green roofs can attenuate housing temperature [9], and this is attributed to the reduction in thermal conductivity $[10,11,12,13]$. However, in residential external walls exposed to the sun and, especially in tall buildings, where wall areas are much greater than roof areas, it is expected the role of green walls in mitigating extreme temperatures is significant. Thus, the combination of green roofs and green walls is expected to promote better thermal performance in residential building envelopes. This research sought to explore to what extent this was the case, using a modular vegetated system as a retrofit covering for walls and roofs.

It is important to analyse the heat effect in terms of human impact, since heat stress may affect populations with adverse health consequences. According to Robinson [14], integration of meteorological elements must be used for the human evaluation of heat effects. The estimate of human heat exposure is based on environmental studies that use indices to capture the combination of several weather factors [15]. Steadman's apparent temperature [16-18] is one of the most popular indices for environmental health research. It combines air humidity and temperature into a single scale; adopting the same units as air temperature. The calculation of apparent temperature, based on original Steadman equations, requires the iteration of multiple equations that takes into account heat and moisture transfer. Steadman [16] carried out this calculation for the 
combination of air temperature and moisture, expressed in terms of relative humidity $(\mathrm{RH})$ and dew point temperature, summarised in table format. Further details on how the principles of physiological heat regulation are used to include the effects of humidity and temperature in determination of heat index $(\mathrm{HI})$ values for a specific weather condition is presented in Steadman [16]. As an alternative to the use of Steadman's tables, Anderson [15] identified 21 algorithms that have been developed to reproduce $\mathrm{HI}$ values. One of these algorithms, based on Steadman's theory, is used by the United States (US) National Weather Service (NWS) to provide the base for heat warnings and is adopted in the present work.

The $\mathrm{HI}$ is a combination of $\mathrm{RH}$ and air temperature, which provides the apparent temperature in degrees Celsius or Fahrenheit. This index is used by the National Weather Service (NWS), an agency part of National Oceanic and Atmospheric Administration (NOAA) of the US government, responsible for providing weather forecasts and hazardous weather warnings. According to the Occupational Safety and Health Administration (OSHA), US Department of Labor, the HI can be used to indicate the risk of heat-related illness. Danger and Extreme Danger categories are associated with risk levels that vary from high to very high/extreme risk levels, whereas Caution and Extreme Caution represent low to moderate risks respectively.

This work evaluates the role of extensive, or shallow depth, green roof and green wall technologies in heat stress attenuation. As in previous studies [19-21], vegetation parameters such as substrate, foliage height and leaf area index (LAI) were not taken into account. However, the characteristics of the vegetation used in the experiments lie among previous works carried out by Pandey et al. [22]; Wong et al. [23]; Djedjig et al. [24]; Wong et al. [25] and Lazzarin et al. [26].

According to Pandey et al. [22] in experiments performed in prototypes, foliage height is related to the degree of shading of soil surface, and the lower the foliage height the higher the heat transfer. The combination of foliage height with the density of the vegetation is a crucial factor in thermal performance. As stated by Djedjig et al. [24], the shading effect of foliage decreases substantially the surface temperature of the building envelope. Additional studies corroborate a direct relationship between LAI and the thermal performance, showing a significant influence of foliage density on the thermal behaviour of green roofs $[27,28,29,30,31]$.

In general, vegetation increases the thermal performance, quantified by the $\mathrm{U}$-value of roofs and external walls. Also known as the overall heat transfer coefficient, this parameter indicates the heat transfer through a surface and higher values indicate low insulating levels. According to Wong et al [25], when compared to a non-thermal insulating building, a roof covered by a $100 \mathrm{~mm}$ soil substrate, vegetated with turf reduces the U-value from 2.39 to $1.19 \mathrm{~W} / \mathrm{m}^{2} \mathrm{~K}$. In addition, for extensive green roofs with soil depths varying from 50 to $100 \mathrm{~mm}$, Nichaou et al. [19], Alcazar \& Bass [32] and Castleton [33], demonstrated the role of vegetation in reducing U-values. Castleton [33] stated that besides insulation, the vegetated surfaces provided 
by green roofs and green walls add thermal mass, which is the material capacity to store or absorb energy, providing inertia against temperature fluctuation that results in temperature peak delay in vegetated structures when compared to non-vegetated ones.

In addition to the role of affecting heat loss through the evapotranspiration process, the water content in soils influences their thermal conductivity and thermal mass. Alcazar and Bass [32], Castleton [33], Lazzarin et al. [26], Wong et al. [25], Lin et al [34], Ouldboukhitine et al. [35] and Sun et al. [13] found that thermal performance worsens in wetter soils, as water is a better conductor of heat than air. In comparison to traditional roof design, Lazzarin et al. [26] stated that the thermal performance of green roofs under dry conditions reduces the influx of heat by $60 \%$. However, when the soil is wet evapotranspiration plays an important role, acting as a heat sink $[5,35,36,37]$. The water content in vegetated structures seems to regulate the heat flux simultaneously by altering the conductivity condition of soils, and indirectly through evapotranspiration of the plants. According to Castleton [33], the water content regulates the heat out flux when the evapotranspiration process is considerable.

Considering that $\mathrm{RH}$ plays a relevant role in establishing $\mathrm{HI}$ values, any extra moisture supply provided by evapotranspiration, which may migrate into the vegetated structures, contributes to increase the RH levels, counteracting the internal temperature attenuation promoted by the plants.

The $\mathrm{HI}$, also known as the apparent temperature, is the combination of what the temperature feels like to the human body when air moisture and temperature are combined. This has important considerations for human body comfort [15]. Rather than temperature itself, $\mathrm{HI}$ is used in the evaluation of heat stress in smallscale experiments, where identical prototypes (vegetated and non-vegetated) are compared using blockwork and timber-framed structures for Rio de Janeiro, Brazil and Sydney, Australia respectively.

Both countries are predicted to be affected severely by increased temperatures in the coming decades as climate change impacts. It will be necessary to retrofit many existing buildings, in a relatively short time frame. Furthermore, many developing countries will be severely affected by increased temperatures [38] and this research aimed to test lightweight, low-cost systems that could be used for retrofitting without the need for additional structural reinforcement to most existing wall and roof types. The research objective was to develop and test practical solutions that can be retrofitted quickly when needed. This paper sets out the rationale for the research design and the experimental setups, focussing on the implementation of low-cost, affordable technologies. The results of the experiments are presented, followed by a discussion of the datasets before conclusions are drawn.

This proposal focussed on affordability and low maintenance aspects. Low-income groups are far more vulnerable to heat stress, which also impacts on health and well-being. As a result, both experimental setups 
made use of simple technologies. In Rio de Janeiro, the materials came from recyclable resources, reusing vaccine boxes for the vegetated system on the walls. In Sydney, the use of document holders, available at stationery stores formed the vertical plant holders. For both sites, low-cost plastic trays were used for the vegetation on the roofs. The Sydney trays were fabricated using 3D printers. These materials were accessible, simple and affordable. Adoption of accessible, simple and affordable materials enables the application of these types of vegetated systems on a large scale, and is not restricted to the service of specialised companies. He et al. [39] planted succulents in a modular rooftop system and found these plants provide excellent insulation $[31,36,40,41]$. Ease of and low maintenance were important criteria and succulent plants were used due to their drought resistant characteristics, low risk of fire, and ability to grow in shallow substrates that do not require structural reinforcement to many typical existing roof and wall structures.

\section{Research Methodology and Experimental Design}

This research adopted a quantitative experimental approach to data collection. The methodology comprises the use of adaptive building technologies to assist in mitigation of problems caused by increased urbanisation and climate change, such as the UHI effect and increased internal housing temperature.

Given that temperature increase and rapid urbanisation occur mainly in developing countries, low-cost techniques based on lightweight modular systems (modular containers) that enable off-site planting, cultivation and maintenance were adopted. Due to increasing building density in urban areas, envelopes may become more relevant than roof areas in terms of heat exchange. In tall residential buildings, it is expected that green walls will have a significant influence in improving heat stress. Greening residential external walls is relevant especially when walls have direct sun exposure.

This research aimed to evaluate the combined effect of green roofs and green walls, and two sets of experiments were performed in Rio de Janeiro, Brazil at the Oswaldo Cruz Foundation (Fiocruz) and at the University of Technology Sydney (UTS), Australia. As depicted in Figure 1 the influence of the combined effect of vegetated roofs and walls in $\mathrm{HI}$ attenuation is carried out comparing two identical housing prototypes. The first is almost fully covered with vegetation, and the second one is not. 


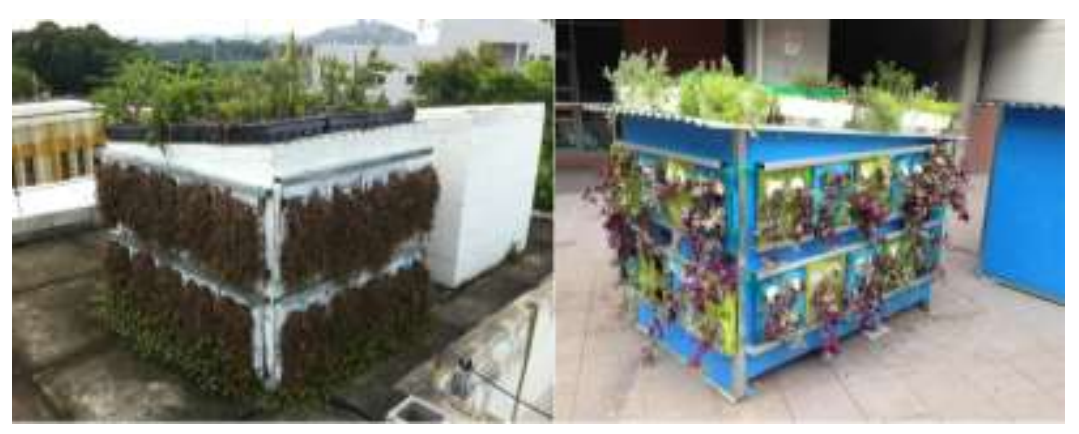
Sydney.

Figure 1: Green roof and green walls experimental setup. Left-hand side - Rio de Janeiro, right-hand side -

Previous studies evaluated the thermal aspects of vegetated prototypes [22-24,42,43]. Due to lack of space and so that the experimental setup would have the same exposure of solar radiation without any neighbourhood shading, the evaluation of the thermal benefits of green roof and walls was performed on an existing building roof. However, due to limitations of structural load bearing capacity, prototypes were used rather than full-scale dwellings.

\section{$2.1 \quad$ Planting: characteristics and set up}

The succulent species used were Crassula Lycopodioides, Crasula Ovalata, Echeveria, Callisia Repens, Sedum, Pachyveria and Tradescantia. There was a mix of these species on the roofs of both sites, while Callisia Repens and Tradescantia were used on the walls. It is important to mention that Callisia Repens had the highest level of coverage (density).

Succulent plants present a Crassulacean acid metabolic (CAM). According to Black and Osmond [44] this type of plant protects its photosynthesis from $\mathrm{CO}_{2}$ and $\mathrm{H}_{2} \mathrm{O}$ stresses, using a mechanism of switching photosynthesis pathways. Thus, succulents comprise a group of plants adapted to extremely arid environments, habitats with intermittent water supply and semi-arid regions with seasonal water availability [41].

In the evaluation of the thermal performance of green roofs, surface albedo influences absorption and reflection of the solar radiation. As Susca et al's [7] study found in a surface covered with sedum, an average albedo of 0.2 was recorded.

In addition to the modular characteristics in this study, green roof systems comprise previously planted vegetated modules placed onto existing roofs covered in metal sheeting or tiles. In this experimental modular system, to avoid loss of soil particles, a permeable fabric separates the substrate from the drainage layer and water storage system. Additional details are described in Wilkinson and Castiglia Feitosa [45]. 
The green wall system was originally designed at Fiocruz (Brazil). It comprises re-used plastic closed boxes, with six squared shaped openings drilled into the lid, in a three row and two-column array. In this case, $5 \mathrm{~cm}$ of substrate depth is provided in the container, and then is covered by the geotextile fabric, before being sealed by the cover of the container box. After this, small cuts are made into the fabric so that the plants can be planted in the system, and after the vegetation development, the boxes are placed in "U" shaped metal profile channels fixed to the wall. The plastic containers for the Sydney experiment had circular openings for planting and adopted identical preparation and wall fixing technologies.

\subsection{Prototypes and climate characteristics}

Although the Rio de Janeiro and Sydney prototypes have the same galvanised steel sheet tile roof covering, they have different structural materials, commonly used in Brazil and Australia respectively. On the Brazilian site, the walls are concrete blocks painted white, whereas in Sydney, a $100 \mathrm{~mm}$ thick timber frame structure covered with drywall painted blue was used. Both prototypes have identical dimensions: $120 \mathrm{~cm}$ width; $150 \mathrm{~cm}$ length; $100 \mathrm{~cm}$ front height and $120 \mathrm{~cm}$ back height. All prototypes are devoid of insulation. The estimated albedo in Rio de Janeiro (white) and Sydney (dark blue) prototype walls was 0.6 and 0.3 respectively. For the galvanised steel roof coverings, the albedo was 0.24 [46].

Rio de Janeiro is located in the southeast region of Brazil and has a warm, humid climate. During the winter, temperatures lower than $15^{\circ} \mathrm{C}$ are unusual and it is common for temperatures to reach $30^{\circ} \mathrm{C}$. In summer periods, temperatures above $30^{\circ} \mathrm{C}$, and occasionally, exceeding $40^{\circ} \mathrm{C}$ are common. In terms of precipitation, the driest months occur from autumn to spring (May to October) and the wettest months in the summer [47].

Sydney is located in the southeast, with a temperate climate shifting from mild and cool in winter, to warm and hot in summer. Monthly averages temperatures range from $8^{\circ} \mathrm{C}$ to $27^{\circ} \mathrm{C}$. Rainfall is fairly evenly spread throughout the year, with moderate to low variability. Slightly higher rates of rainfall occur during the from February to June when easterly winds dominate, and lower rainfall rates are common from July to September [48]. 


\subsection{Heat stress evaluation and measurement methods}

The choice of the use of $\mathrm{HI}$ lies in studies performed by Steadman [16-18] that provide the basis for heat advisories in the US, which has locations (especially in the southern part) with climate characteristics similar to Rio de Janeiro and Sydney. Moreover, according to the study carried out by Anderson et al. [15], HI was widely used as a measure of heat exposure in studies in the U.S., Europe, Australia, Bangladesh, South Korea and in Central and South American countries.

The levels of $\mathrm{RH}$ play an important role in heat stress since it regulates the evaporation rate of sweat from the skin that allows the human body to cool down on hot days. Thus, the higher the $\mathrm{RH}$, the lower the evaporation rate from the skin and the higher the apparent temperature. Besides the similarities between apparent temperature and air temperature for low levels of $\mathrm{RH}$, it is important to highlight that low humidity can be a problem, due to rapid evaporation of sweat. Under these conditions dehydration becomes possible.

According to Anderson et al. [15] in the estimation of heat exposure, many environmental health studies rely on indices that aim to gather several environmental factors. In terms of environmental health research, Steadman's work [16-18] provided the Steadman's apparent temperature that translates air moisture and temperature into a single scale measured in the same units as air temperature, also called the HI.

Based on Steadman's theory [16-18], many algorithms have been developed to calculate $\mathrm{HI}$ as a function of air temperature and RH or dew point temperature. The NWS algorithm [49] showed the best fit to Steadman's table values and was selected therefore in this research to calculate the HI values. This algorithm based on values of temperature $(\mathrm{T})$ in degrees Fahrenheit and $\mathrm{RH}$ in percent is presented in the flowchart in Figure 2.

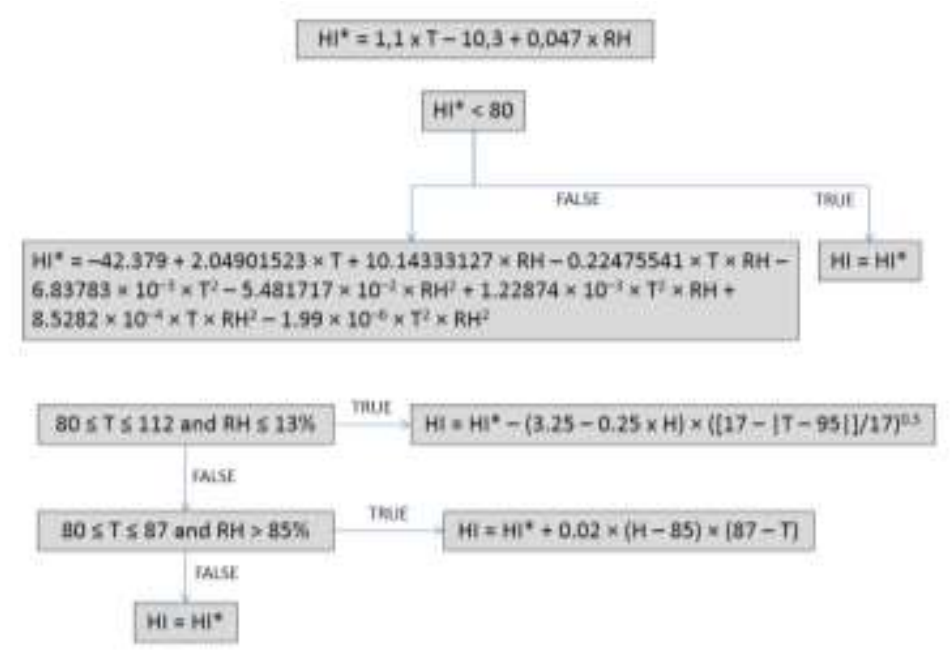

Figure 2: Flowchart of the algorithm of heat index (HI) calculation used by (NWS 2017) based on air temperature in degrees Fahrenheit $(T)$ and relative humidity in percent $(\mathrm{RH})$ 
According to NWS [49], the basis for the HI values calculation comprises shady conditions, and during exposure to direct sunlight, these values can be increased by around $8^{\circ} \mathrm{C}$.

The calculation of $\mathrm{HI}$ was based on registers of $\mathrm{RH}$ and temperature simultaneously recorded every 30 minutes inside the vegetated and non-vegetated prototypes. These measurements were taken using a commercial USB data logger Extech $\mathrm{RHT} 10$, which has a $\mathrm{RH}$ range from 0 to $100 \%$, a temperature $(\mathrm{T})$ range from -40 to $70 \stackrel{\circ}{\circ}(-40$ to $158 \stackrel{\circ}{\circ})$, and an accuracy in $\mathrm{RH}$ and $\mathrm{T}$ of $3 \%$ and $0.6 \stackrel{\circ}{\circ} \mathrm{C}(1 \stackrel{\circ}{\circ})$ respectively. The data loggers were placed about $700 \mathrm{~mm}$ above the floor of the structures, which corresponds, in real scale dwellings, to a level equivalent to the average height of people. Access to the data loggers is through $100 \mathrm{~mm}$ circular openings in the front part of the prototypes. The Rio de Janeiro records comprise a 161-day period from October 31st 2016 to February 8th 2017, and the Sydney tests were performed over 300 days, from January 19th 2016 to November 20th 2016.

\section{Results}

The results of the combination of green roof and walls performed for the two experimental sites are shown in Figures 3 and 4.

It is important to note the following results present two different and separate case studies, carried out under different experimental setup and climate conditions: a temperate climate (Sydney) and a warm and humid climate (Rio de Janeiro). Thus, no attempt is made to perform any comparison between the different sites. Sydney and Rio de Janeiro were selected for the experiments as both are coastal cities in the southern hemisphere which are experiencing rapid urbanisation and increasingly high temperatures over extended periods. In many parts of both cities it is less affluent people living in properties, often designed without consideration of excess heat gain and thermal comfort, that are poorly constructed and, as a result, who experience the discomfort that arises through excessively high temperatures. Furthermore with ageing populations the potential negative health impacts of excess temperature increase. The rationale for selection of the cities was to explore options for low-cost, lightweight retrofit modules that could be affordable options for those experiencing heat stress in housing.

This paper evaluates retrofitted green roofs and green walls on small-scale structures replicating construction technologies typically adopted in local housing design. Even though under the different structural schemes adopted on the Rio de Janeiro and Sydney sites, a significant attenuation in $\mathrm{HI}$ or apparent temperature is evident when comparing the control structures to the fully vegetated prototypes. 


\subsection{Rio de Janeiro case study}

Figure 3 presents a comparison between $\mathrm{RH}$, temperature, and calculated $\mathrm{HI}$ according to the NWS algorithm, over 161 days that covered the mid-winter and mid-summer season. The lower lines in the graphs represent the differences between the non-vegetated and vegetated prototypes for temperature and $\mathrm{HI}$ graphs, whereas for $\mathrm{RH}$ it represents the opposite.

A summary of the maximum, minimum, and average registers of temperature, $\mathrm{RH}$, and their associated values of $\mathrm{HI}$ for both the vegetated and non-vegetated prototypes is shown in Table 1.

\begin{tabular}{lcccccc}
\hline & \multicolumn{2}{c}{ Temperature $\left({ }^{\circ} \mathrm{C}\right)$} & \multicolumn{2}{c}{ Relative humidity (\%) } & \multicolumn{2}{c}{ Heat index ( $\left.{ }^{\circ} \mathrm{C}\right)$} \\
Vegetated & $\begin{array}{c}\text { Non- } \\
\text { vegetated }\end{array}$ & Vegetated & $\begin{array}{c}\text { Non- } \\
\text { vegetated }\end{array}$ & Vegetated & $\begin{array}{c}\text { Non- } \\
\text { vegetated }\end{array}$ \\
\hline Maximum & 39.2 & 45.3 & 95.0 & 93.8 & 49.2 & 57.5 \\
Minimum & 18.2 & 17.3 & 30.4 & 26.3 & 18.2 & 17.2 \\
Average & 27.0 & 28.1 & 72.2 & 66.6 & 29.5 & 30.9 \\
\hline
\end{tabular}

Table 1: Rio de Janeiro maximum, minimum and average limits of temperature, relative humidity and heat index.

Regarding the $\mathrm{RH}$, all limits presented for the vegetated prototype were mostly higher than for the nonvegetated prototype. Opposite to temperature, minimum values of $\mathrm{RH}$ occur when the temperature is higher and vice versa. In addition, the maximum records for both the vegetated and non-vegetated prototypes indicate the extremely humid climate of Rio de Janeiro.

The $\mathrm{RH}$ registers of the vegetated prototype were permanently higher than the non-vegetated prototypes even for the lower temperature levels, indicating, due to the transpiration of the plants, a moisture migration into the housing prototype.

The highest temperatures occurred during the daytime and the lowest along the night-time around early morning hours. 


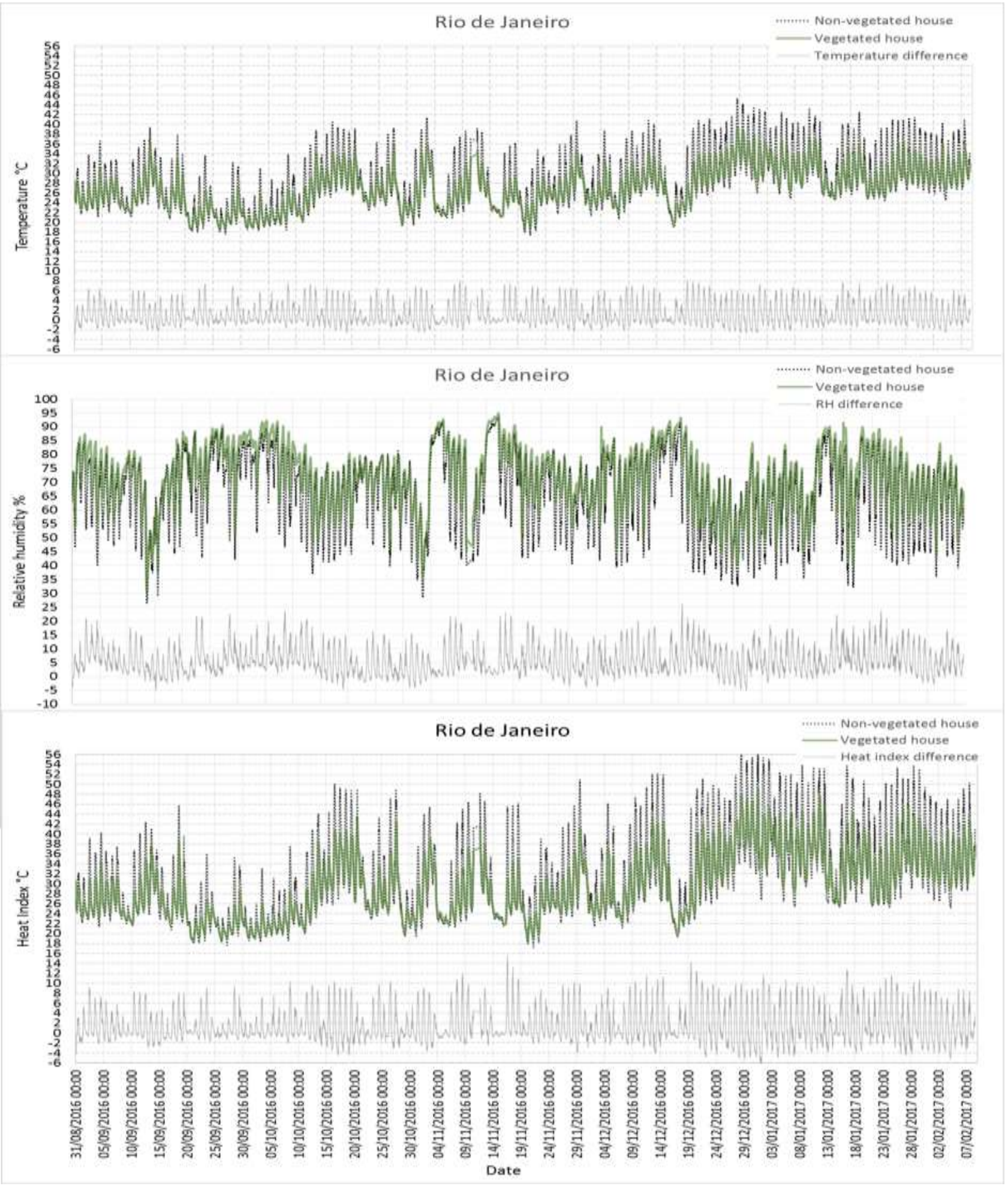

Figure 3: Rio de Janeiro - comparisons between relative humidity, temperature, and calculated heat index.

The temperature attenuation is evaluated through the simultaneous temperature difference between the non-vegetated and the vegetated prototypes, where positive values indicate higher temperatures in the nonvegetated prototype and negative values indicate the opposite. As shown in Figure 3, temperature differences 
ranged between $-2.8^{\circ} \mathrm{C}$ and $8.1^{\circ} \mathrm{C}$. Throughout the dataset, the non-vegetated prototype had its temperatures higher (positive differences) during the daytime and lower (negative differences) during night-time and early morning. The highest positive temperature differences occurred slightly after midday, whereas the maximum negative differences were evident in the early morning periods, which show the influence of the vegetation in attenuating heat exchange and adding thermal mass.

Compared to previous work carried out by Wilkinson and Castiglia Feitosa [45] where only the roof surface was covered with vegetation, the addition of green walls to a previously vegetated roof increases the temperature differences between the non-vegetated and vegetated prototypes even more. In the aforementioned work, temperature differences varied from $-1.5^{\circ} \mathrm{C}$ to $5.6^{\circ} \mathrm{C}$; the additional effect of green walls altered these limits to positive and negative limits of $8.1^{\circ} \mathrm{C}$ and $-2.8^{\circ} \mathrm{C}$ respectively. However, it is important to highlight that the increase in the negative limit was more pronounced than in the positive, indicating a good performance in heat loss during night-time periods.

In comparison to temperature, the maximum levels observed for the $\mathrm{HI}$ were substantially higher. With regards to average limits, the values for the $\mathrm{HI}$ are slightly higher. The similar values for the minimum limits lie on the algorithm assumption's that the $\mathrm{HI}$ is quite similar to temperature for low limits $\left(T<26.7^{\circ} \mathrm{C}\right)$ of this parameter. However, it is important to highlight that the $\mathrm{HI}$ values depend on the simultaneous combination of temperature and $\mathrm{RH}$ that present an inverse relationship between them.

In terms of the $\mathrm{HI}$ analysis, the differences between the non-vegetated and the vegetated prototypes varied from $-7.6^{\circ} \mathrm{C}$ to $15.5^{\circ} \mathrm{C}$, widening those limits observed for temperature. Similarly, the highest positive differences occurred during the daytime periods and the highest negative differences during night and early morning periods.

Regarding the temperature, $\mathrm{RH}$ and $\mathrm{HI}$ differences presented in Figure 3, when comparing the vegetated to the non-vegetated prototypes, a more similar pattern between $\mathrm{HI}$ and temperature was observed, which indicates a stronger influence of temperature on $\mathrm{HI}$. Based on this pattern similarity, the maximum negative differences (depicted in the upper graph of Figure 4) show that the periods when the $\mathrm{HI}$ of the vegetated prototype are higher than the non-vegetated prototype occurred early in the mornings. This occurred during a combination of higher $\mathrm{RH}$ and temperature in the vegetated prototype, over days of successive high temperature levels. This is attributed to the capability of vegetation to flatten the temperature fluctuation due to the attenuation in heat exchange ( $\mathrm{U}$-value reduction) and the addition of thermal mass, together with higher $\mathrm{RH}$ levels even under events of higher temperature. In the lower graph within Figure 4, maximum positive differences were observed subsequent to events of nearly zero temperature differences, combined with sudden falls of this parameter. In this case, due to inertia in heat exchange, it takes some time to achieve 
warmer conditions in the vegetated prototypes during the early morning, which results mainly in the permanent, cooler conditions of the vegetated prototype in the first days after these events.
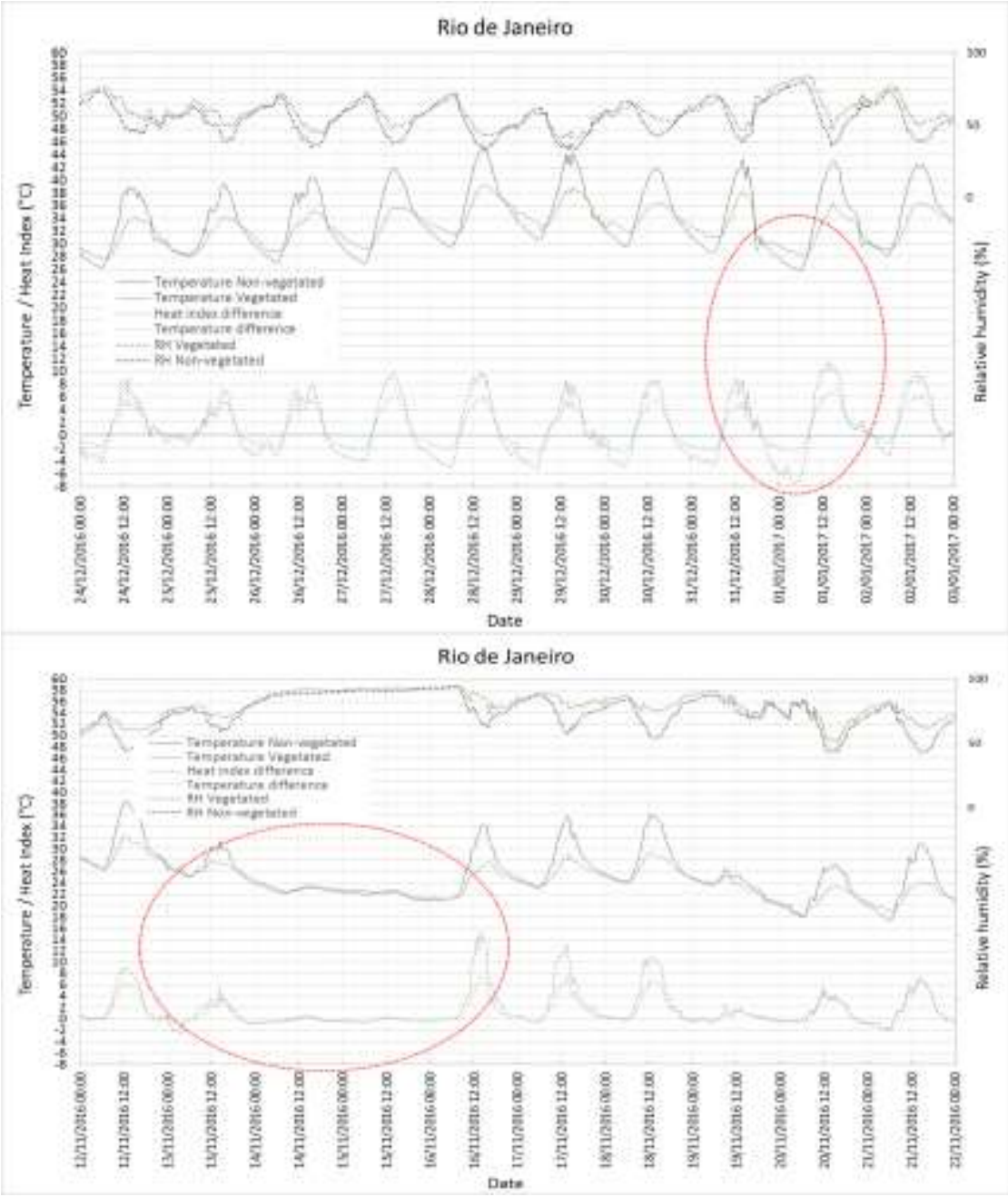

Figure 4: Rio de Janeiro - Details in temperature, relative humidity and heat index patterns along conditions of maximum negative differences (upper part) and maximum positive (lower part).

Compared to the non-vegetated prototype, the influence of vegetation in $\mathrm{HI}$ attenuation was influenced by $\mathrm{RH}$ levels. The higher the difference of $\mathrm{RH}$ between the vegetated and non-vegetated prototypes, the lower the attenuation in $\mathrm{HI}$ levels. During these episodes, speaking in terms of "apparent temperature" the vegetated prototype became warmer more often than the non-vegetated one, exclusively due to the effects of high levels of $\mathrm{RH}$ that are able to offset the temperature attenuation promoted by the vegetation.

Figure 5 presents a heat stress assessment through the comparison of the percentage of time that the $\mathrm{HI}$ of the vegetated and non-vegetated prototypes lie on the categories of heat advisories according to the NWS classification. Based on this figure the percentage of time considered, over the 161 days, as conditions of 'Extreme Caution', 'Danger' and 'Extreme Danger' could be reduced from 39.1 to $34.5 \%$. However, under 
conditions of extreme levels of heat exposure, such as 'Dangerous' and 'Extremely Dangerous', the vegetated prototype reduced these conditions from $14.1 \%$ to $4.4 \%$ when compared to the non-vegetated prototype. This result may have substantial health impacts in terms of the probability of heat stroke reduction, especially in the elderly population.

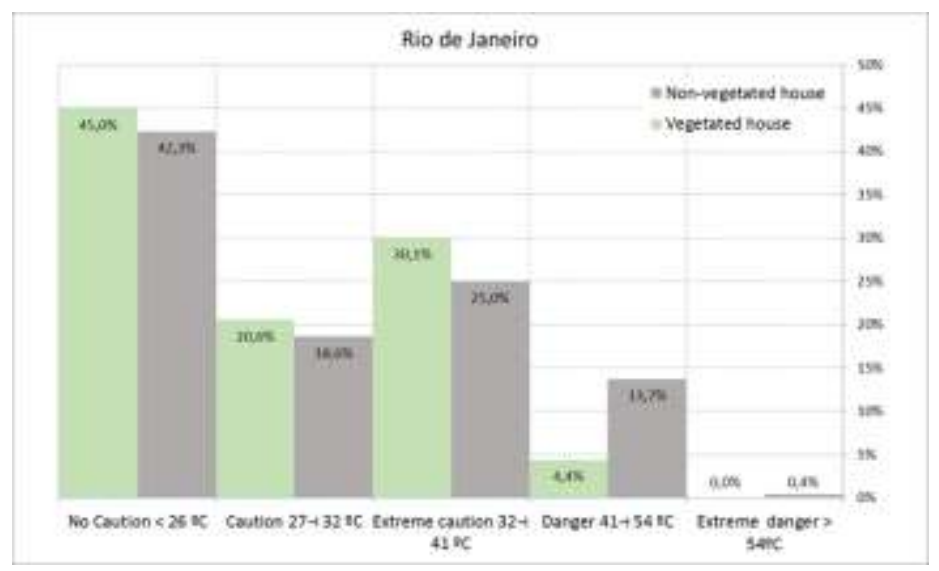

Figure 5: Rio de Janeiro - Heat stress assessment. Percentage of time that heat index of vegetated and non-vegetated prototypes lie on the categories of heat advisories according to the NWS classification.

\subsection{Sydney case study}

A comparison between $\mathrm{RH}$, temperature, and calculated $\mathrm{HI}$ according to the NWS algorithm, is presented during a 300 day-period that comprises mostly summer and mid-spring seasons (southern hemisphere) in Figure 6. In each graph, the bottom lines represent temperature and $\mathrm{HI}$ and the differences between the non-vegetated and vegetated prototypes. As for $\mathrm{RH}$, it means the inverse relation (vegetated minus non-vegetated). In addition, the maximum, minimum and average of the measured parameters of $\mathrm{RH}$ and temperature, and their associated values of the $\mathrm{HI}$ for both the non-vegetated and vegetated prototypes are summarised in Table 2.

\begin{tabular}{ccccccc}
\hline & \multicolumn{2}{c}{ Temperature } & \multicolumn{2}{c}{ Relative humidity } & \multicolumn{2}{c}{ Heat index } \\
& Vegetated & $\begin{array}{c}\text { Non- } \\
\text { vegetated }\end{array}$ & Vegetated & $\begin{array}{c}\text { Non- } \\
\text { vegetated }\end{array}$ & Vegetated & $\begin{array}{c}\text { Non- } \\
\text { vegetated }\end{array}$ \\
\hline Maximum & 33.0 & 42.0 & 92.5 & 89.5 & 36.3 & 55.9 \\
Minimum & 7.2 & 7.4 & 19.9 & 17.6 & 5.7 & 5.8 \\
Average & 18.9 & 19.8 & 67.0 & 61.6 & 18.7 & 19.7 \\
\hline
\end{tabular}

Table 2: Sydney maximum, minimum and average limits of temperature, relative humidity and heat index.

All limits of $\mathrm{RH}$ observed for the vegetated structure were higher, indicating a possible moisture supply into the prototypes due to plants' transpiration. For all datasets, the $\mathrm{RH}$ values observed for the vegetated structure were permanently higher when compared to the non-vegetated structure. 
The highest temperatures occurred during the afternoon and the lowest in early morning. Compared to temperature, the maximum limits of the $\mathrm{HI}$ were higher, the average values did not differ significantly and the minimum limits were the same.

As for temperature attenuation, according to Figure 6 the simultaneous temperature differences varied from $-1.2^{\circ} \mathrm{C}$ to $12.0^{\circ} \mathrm{C}$, where the positive differences (the non-vegetated prototype was warmer than the vegetated one) occurred during the daytime and negative differences were common in the night-time and the early morning.

When compared to temperature, the maximum values of the $\mathrm{HI}$ were substantially higher for the nonvegetated prototypes. The differences observed between the non-vegetated and the vegetated structures ranged from $-3.0^{\circ} \mathrm{C}$ to $21.8^{\circ} \mathrm{C}$. Comparing these limits to the ones observed for temperature, it is observed that the efficiency of vegetation in attenuation of "apparent temperature" is even more pronounced, showing it to be more effective in avoiding heat inflow rather than heat outflow. The temperature effect was determinant on the $\mathrm{HI}$, once the differences observed between the non-vegetated and the vegetated structures were substantial, and also due to the similar patterns observed of the differences between non-vegetated and vegetated prototypes depicted in Figure 6. Moreover, compared to the non-vegetated prototype, the levels of $\mathrm{RH}$ in the vegetated prototype were not high enough to counteract the effects of the temperature attenuation promoted by the vegetation. Thus, the considerable temperature attenuation promoted by vegetation is substantially converted in $\mathrm{HI}$ reduction when compared to the non-vegetated prototypes.

The maximum negative differences, which means higher $\mathrm{HI}$ in the vegetated prototype, also occurred in the early morning, highlighted by the elliptical dotted line on the left in Figure 7 . This can be attributed to periods of higher temperature in the vegetated prototypes, combined with higher levels of $\mathrm{RH}$. In Figure 7 , highlighted on the right by a dotted ellipse line, the maximum positive differences occurred after events of similar temperatures between the non-vegetated and the vegetated prototypes, combined with previous sudden temperature falls. When similar temperatures occur, the subsequent heat gain is substantially attenuated in the vegetated prototypes, whereas this does not occur in the non-vegetated prototypes.

The $\mathrm{RH}$ levels observed in the vegetated prototype was not high enough to offset the substantial temperature differences between the non-vegetated and vegetated prototypes, and thus, a much more pronounced attenuation in $\mathrm{HI}$ was observed. It is important to highlight that the substantial temperature attenuation lies somehow in the experimental setup adopted, and this is commented on, in the following sections of this paper. 


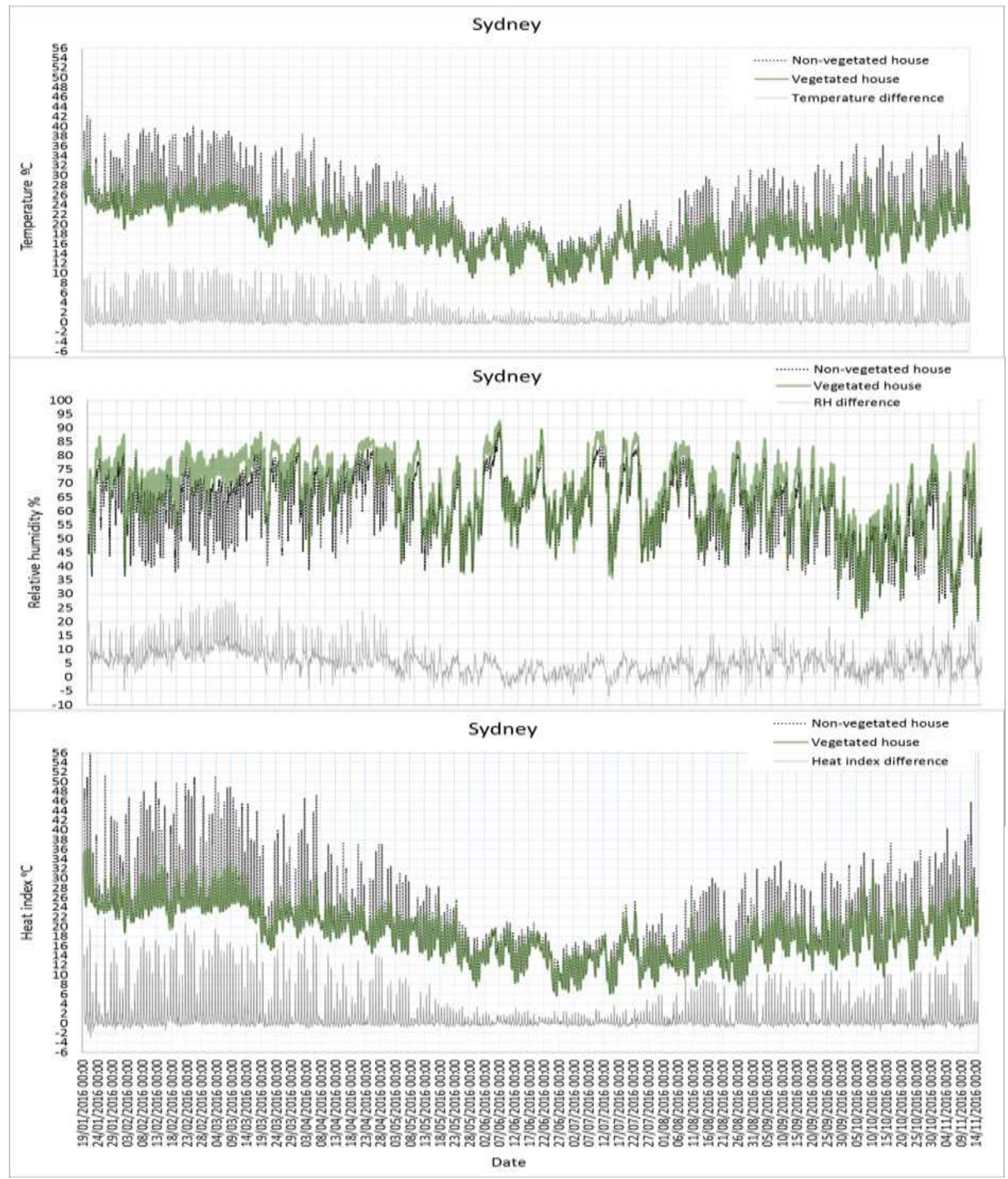

Figure 6: Sydney - comparisons between relative humidity, temperature, and calculated $\mathrm{HI}$.

The evaluation of the heat stress assessment is shown in Figure 8 and presents a comparison between the $\mathrm{HI}$ of the vegetated and the non-vegetated prototypes, based on the percentage of time that their values lie on the heat advisories categories. According to Figure 8, the percentage of time, over the 300 days period, 
the days where conditions of 'extreme caution', 'danger' and 'extreme danger' prevailed, could reduce from $4.4 \%$ to $0.4 \%$.

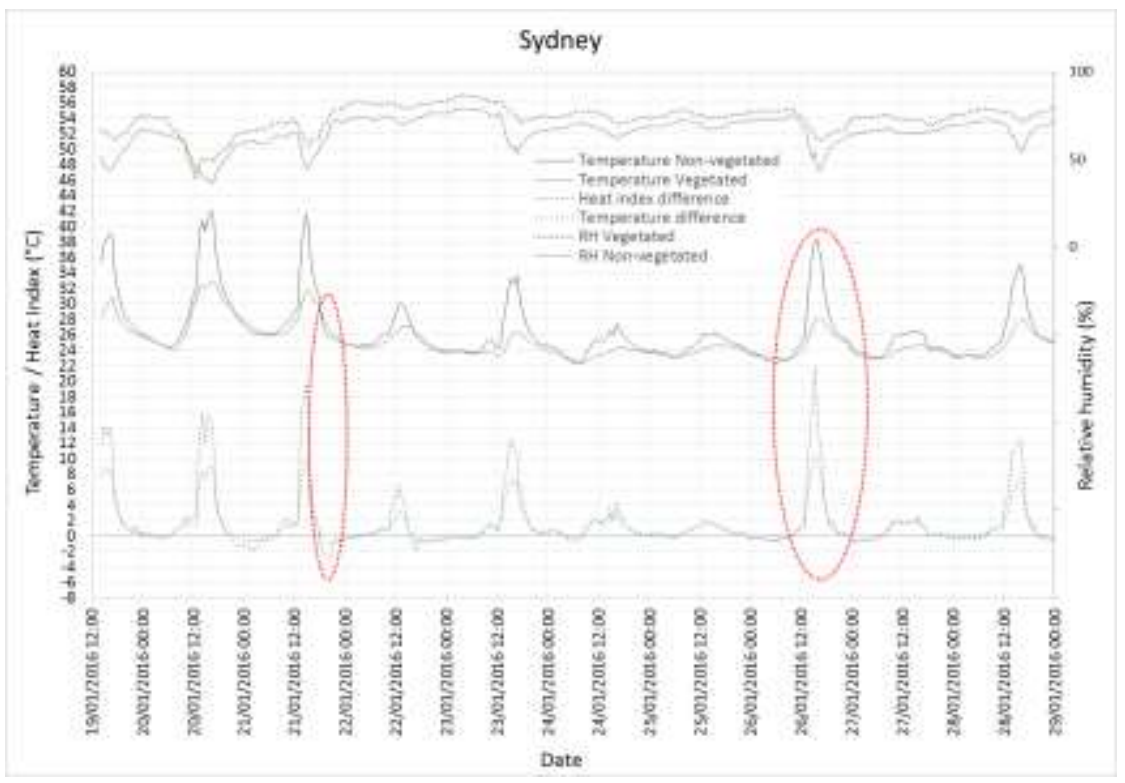

Figure 7: Sydney - Details in temperature, relative humidity and heat index patterns along conditions of maximum negative differences (left dotted ellipse) and maximum positive (right dotted ellipse).

Comparing vegetated to non-vegetated prototypes situations of 'Danger' and 'Extreme danger' could be reduced from $1.3 \%$ to $0.0 \%$.

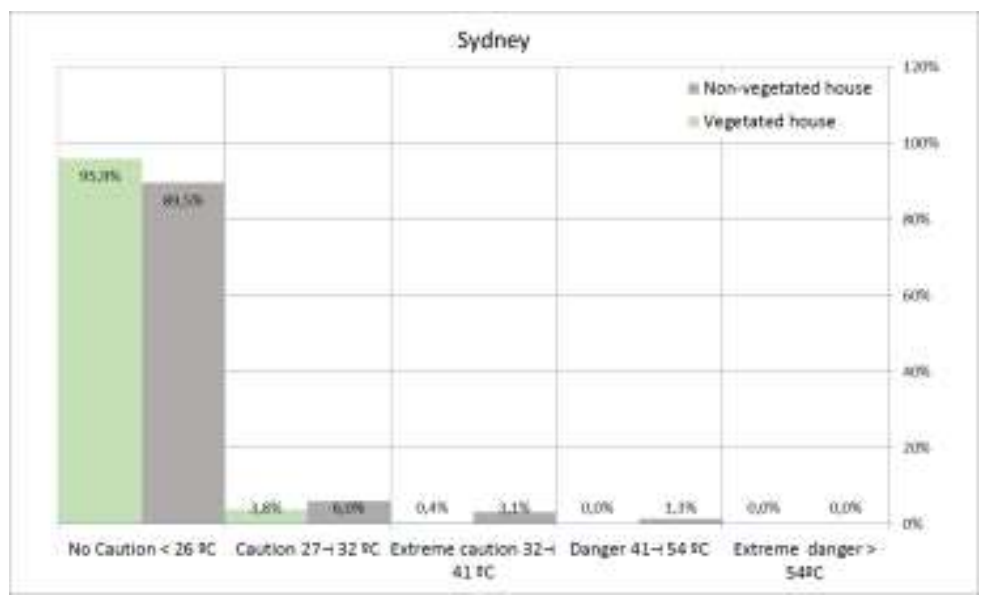

Figure 8: Sydney - Heat stress assessment. Percentage of time that heat index of vegetated and non-vegetated prototypes lie on the categories of heat advisories according to the NWS classification.

\section{$4 \quad$ Discussion}

In relation to previous work carried out by Wilkinson and Castiglia Feitosa [45] where only the influence of vegetated roofs was considered in assessing temperature attenuation, the addition of vegetation on external walls in the Rio de Janeiro experimental set-up increased the temperature differences between the non- 
vegetated and the vegetated prototypes. Djedjig et al. [24], also using small-scale prototypes, reported comparable results under experimental conditions quite similar to Rio de Janeiro, where white external walls were compared to vegetated external walls.

Pastore et al. [50] in a multi-scale approach showed the effectiveness of vegetation in controlling indoor and outdoor thermal comfort, through the assessment of the influence of green walls, green roofs, and the addition of outdoor vegetation in indoor temperatures. The outdoor vegetation and the green walls presented a significant role in attenuating indoor temperatures. Green roofs had a considerable effect only in top floor apartments.

As far as temperature is concerned, the Sydney experiments presented considerable differences between the non-vegetated and the vegetated prototypes. It may be attributed to the blue colour paint used on the walls that increased internal temperature differences, due to the contrast of the surface temperatures between the non-vegetated walls and the walls shaded and screened by vegetation. Considering the Sydney experimental setup is new, no previous data are available to perform a comparison between a fully covered (walls and roof) and roof covered only structures.

As noted in the research methodology section, the evaluation of temperature attenuation of green roof and green walls was carried out on prototypes, rather than real dwellings. However, previous studies validate the temperature attenuation of green roofs and/or green walls also comparing vegetated to non-vegetated prototypes [22,23,24,28,42]. During a one day comparison, Pandey et al. [22] using brickwork prototypes with similar dimensions to the ones used in the present study, found temperature differences between traditional roof and green roof prototypes of about $4^{\circ} \mathrm{C}$. In the Rio de Janeiro experiments performed on brickwork prototypes, the temperature differences presented here are significantly higher. However, it must take into account, that this increase can be attributed to the addition of green walls to an existing green roof prototype. Previous work by Wilkinson and Castiglia Feitosa [45] where only the influence of green roofs on temperature attenuation was considered, found similar results to Pandey et al. [22].

Several works have shown the potential of green roofs to attenuate indoor temperature $[10,20,23,25,27$ $33,36,39,41,51$ ]. According to Fioretti et al. [51] this occurs due to the attenuation of solar radiation through the vegetation layer, as well as to the thermal insulation performance of the green roof structure.

Niachou et al. [19] investigated thermal performance of a green roof in a real building. Comparing two similar insulated buildings with, and without, a green roof; a reduction in temperature up to $3^{\circ} \mathrm{C}$ was observed. Thus, for non-insulated buildings, a higher reduction in temperature for buildings with green roofs is expected. Another study performed by Parizotto and Lamberts [20], evaluated, in the same residential building, the role of green roofs compared to two different roof types: ceramic tiles and sheet metal. During warm periods, the 
air temperature of the room below the green roof was up to $1.5^{\circ} \mathrm{C}$ lower than rooms below the sheet metal and ceramic tiled roofs. This difference was not pronounced due to characteristics of the experimental setup, since all parameters and data have been gathered in insulated rooms with different heights, geometry and roof slopes. Moreover, at any given time, the shading is not the same for the roofs evaluated. Furthermore, the white colour of the ceramic tile roof covering helps to reflect incoming solar radiation, and the sheet metal covering is white and has solar photovoltaic panels which shade most parts of the roof surface. It is important to highlight that the room under the green roof has the smallest volume and ceiling height, and is thus expected to respond faster than the other rooms. In other words, according to Parizotto and Lamberts [20], the room directly below a green roof outperformed the other rooms evidencing the efficiency of green roofs in thermal performance.

It is important to consider that the present work does not intend to extrapolate the results to real conditions, but instead, to compare under identical outdoor conditions the effects of vegetation on the attenuation of heat stress in dwellings using $\mathrm{HI}$ for its evaluation. Rather than consider the single effect of temperature, $\mathrm{HI}$ considers the combined effect of this parameter with $\mathrm{RH}$ in the evaluation of heat exposure in human health. Taking into account that $\mathrm{HI}$ values higher than $41^{\circ} \mathrm{C}$ can lead to dangerous heat disorders under prolonged exposure and/or physical activity, the Rio de Janeiro results (Figure 5) showed that the combination of the vegetated roof and walls can diminish dangerous heat conditions around $10 \%$ of the time. Comparatively, such conditions occurred $14.1 \%$ of the time in the non-vegetated prototype and only $4.4 \%$ of the time in the vegetated prototype.

Due to the milder climate conditions, Sydney's results (Figure 8) showed that such conditions reduced the occurrence $1.3 \%$ of the time in the non-vegetated prototype to $0 \%$ in the vegetated prototype. However, due to the climate change effects this occurrence may increase over time. Figure 9 shows a summary of $\mathrm{HI}$ differences (percentage) according to different ranges of attenuation.

Comparing the un-vegetated and vegetated prototypes, and considering a significant thermal attenuation for ranges of $\mathrm{HI}$ differences higher than $5^{\circ} \mathrm{C}$, an occurrence of $16.3 \%$ was observed in Rio de Janeiro. This means, that on approximately 26 out of 161 days, there was a significant reduction in $\mathrm{HI}\left(>5^{\circ} \mathrm{C}\right)$ through the use of green walls and a green roof.

In Sydney, this occurrence was $6.6 \%$, and thus it meant a reduction in $\mathrm{HI}$ of such magnitude in about 20 out of 300 days. The remarks above, regarding the percentages presented, aim to evaluate the potential of $\mathrm{HI}$ attenuation through the use of vegetation in the prototypes. 


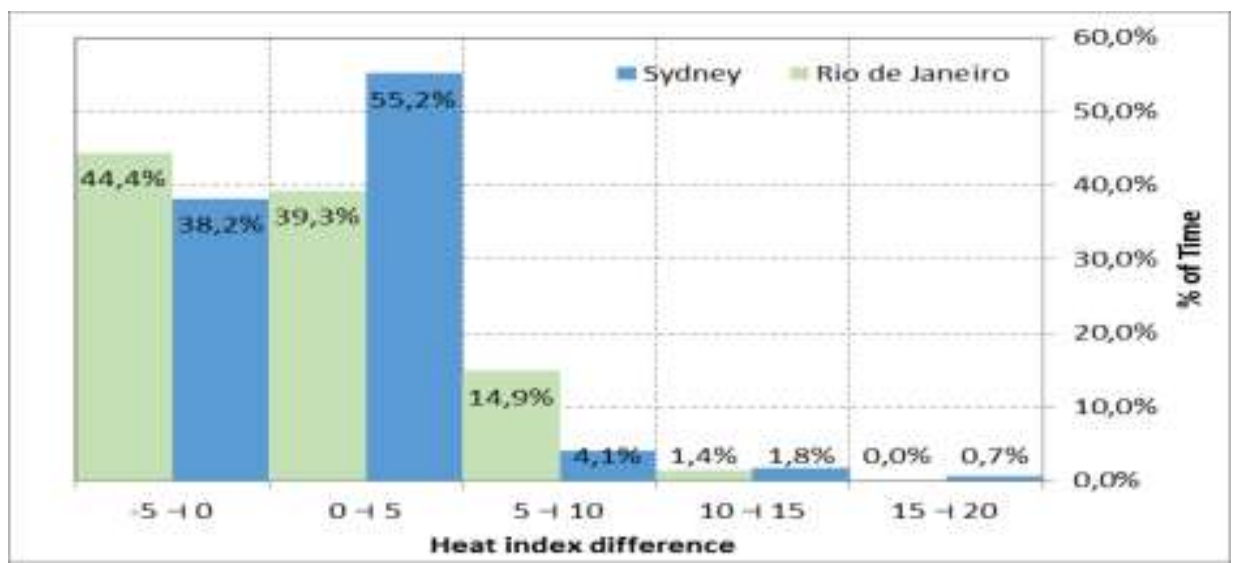

Figure 9: scattered data points of $\mathrm{HI}$ attenuation between the non-vegetated and the vegetated prototypes for Rio de Janeiro and Sydney experiments (upper and centre graphs). The histogram presents the percentage of the time according to the ranges of the $\mathrm{HI}$ differences observed between vegetated and non-vegetated prototypes.

The $\mathrm{RH}$ of the vegetated prototypes was higher than the non-vegetated structure most of the time, even when the vegetated structures were warmer. This indicates the influx of moisture from plant transpiration in the vegetated structures. Notwithstanding, it is expected that construction details may eliminate the influx of moisture to the prototypes, using an impervious layer in the walls, as well as the closure of minute air gaps that exist between the junctions of the roofs and walls.

\section{$5 \quad$ Conclusions}

The present study is not a direct comparison between the Rio de Janeiro and the Sydney sites, due to their different climates and construction materials used in the respective experimental setups. This work evaluated the thermal benefits of an extensive green roof and green walls considering two different cases studies: Rio de Janeiro and Sydney. The results showed a good potential for the use of vegetated modular systems in attenuating temperature and the $\mathrm{HI}$.

In terms of simultaneous differences in temperature and $\mathrm{HI}$, high values were observed at the Sydney site, due to blue colour (low albedo) used on the walls of the prototypes. This resulted in high internal temperature differences, due to the contrast of the surface temperatures between the non-vegetated walls and the walls shaded and screened by vegetation.

In the Rio de Janeiro dataset, $\mathrm{HI}$ attenuation higher than $15^{\circ} \mathrm{C}$ did not occur. For ranges between $10^{\circ} \mathrm{C}$ and $15^{\circ} \mathrm{C}$, and $5^{\circ} \mathrm{C}$ to $10^{\circ} \mathrm{C}$, the occurrences were $1.4 \%$ and 14.9 , respectively.

In the Sydney experiments, $\mathrm{HI}$ attenuation between $15^{\circ} \mathrm{C}$ and $20^{\circ} \mathrm{C}$ was observed over $0.7 \%$ of the duration of the experiment. For ranges in $\mathrm{HI}$ attenuation between $10^{\circ} \mathrm{C}$ and $15^{\circ} \mathrm{C}$, there was a slightly higher 
occurrence of $1.8 \%$. However, it is important to highlight that $\mathrm{HI}$ attenuations from $5^{\circ} \mathrm{C}$ to $10^{\circ} \mathrm{C}$ occurred $4.1 \%$ of the time.

The Rio de Janeiro results showed the combination of a vegetated roof and walls can diminish dangerous heat conditions approximately $10 \%$ of the time. Due to milder climate conditions observed in Sydney, the occurrence of 'danger' conditions reduced from $1.3 \%$ of the time in the non-vegetated prototype to $0 \%$ in the vegetated prototype.

In both the Rio de Janeiro and the Sydney sites, the RH of the vegetated prototypes had higher levels over almost all of the dataset, which indicates the influx of moisture in the vegetated structures due to the transpiration of the plants.

The combination of $\mathrm{RH}$ and temperature is determinant in establishing $\mathrm{HI}$ parameter to evaluate the thermal benefits of vegetated systems. Thus, the additional moisture supply from the transpiration of the plants may migrate into the vegetated structure and counteracts the temperature attenuation promoted by the plants. This became more evident in the experiments performed in Rio de Janeiro for similar levels of temperature between vegetated and non-vegetated prototypes. On some occasions, due to the higher moisture levels the $\mathrm{HI}$ in the vegetated prototype exceeds those observed in the non-vegetated prototype.

The experimental setups here have some limitations regarding construction, such as small openings between the roofs and walls that allow the passage of moisture into the prototypes. However, the prototypes used in the Rio de Janeiro experiments have similar characteristics to most housing for people on lower incomes, where concrete slabs are not used and roof coverings comprise tiling only. These specifications are common in low-income areas where most dwellings experience the worst conditions in terms of heat exposure. Thus, it is expected that eliminating these deficiencies may reduce the $\mathrm{RH}$ levels inside the vegetated prototype and consequently lower the HI values.

The addition of vegetation to the walls of an existing prototype with its roof previously covered with vegetation resulted in higher temperatures in the vegetated prototype during night and early morning periods, and higher temperatures in the non-vegetated prototype during daytime periods. The combination of the vegetated roof and walls increased, not only the insulating properties of the external walls, but also added thermal mass.

Taking into account the increasing height and density of buildings in urban centres the combined use of green walls and green roofs is desirable for thermal stress attenuation.

Even considering the experimental scale adopted in the present work, it is vital to highlight that the combination of the vegetated roof and walls was important in temperature and $\mathrm{HI}$ attenuation. It is expected 
that vegetated walls have much higher relevance in attenuating heat stress in buildings since external wall areas are significantly greater than roof areas.

It is acknowledged that the real scale prototypes present a better scenario than experimental setups. However, it presents many constraints regarding higher setup costs, available area to consider the same environmental aspects and limitations of operational conditions under long-term evaluation. Thus, even though these structures are not perfect examples of real conditions, small-scale prototypes allow comparisons that on some occasions are not possible to perform in full-scale dwellings.

\section{$6 \quad$ References}

01. RICS Futures: Our Changing World. Accessed on 13th August 2016 from www.rics.org (2016)

02. Oke TR. Urban Climates and Global Environmental Change, In: Thompson, R.D. and A. Perry (eds.) Applied Climatology: Principles \& Practices (1997). New York, NY: Routledge. pp. 273-287

03. Alexandria E, Jonesb P. Temperature decreases in an urban canyon due to green walls and green roofs in diverse climates. Building and Environment, (2008) 43: 480-493.

04. Yaghoobian N, Srebric J. Influence of plant coverage on the total green roof energy balance and building energy consumption. Energy and Buildings (2015), 103: 1-13.

05. Takebayashi H, Moriyama M. Surface heat budget on green roof and high reflection roof for mitigation of urban heat island. (2007) 42: 2971-9.

06. Solcerova A, van de Ven F, Wang M, Rijsdijk M, van de Giesen N. Do green roofs cool the air? Building and Environment, (2017) 111: 249-255.

07. Susca T, Gaffin SR and Dell'Osso. Positive effects of vegetation: urban heat island and green roofs. Environmental Pollution (2011) 159: 2119-26

08. Herrera-Gomez SS, Quevedo-Nolasco A, Perez-Urrestaraz L. The role of green roofs in climate change mitigation. A case study in Seville (Spain). Building and Environment (2017), 123: 575-584.

09. Wilkinson SJ, and Castiglia Feitosa R. Thermal Performance in Green Roof Retrofit, in Green Roof Retrofit: building urban resilience, edited by S. J. Wilkinson and T. Dixon (Wiley-Blackwell, London, 2016), pp. 62-84.

10. Del Barrio EP. Analysis of the green roofs cooling potential in buildings. Building and Environment. (1998) 27: 179-193.

11. Pianella A, Clarke RE, Williams NSG, Chen Z, Aye L. Steady-state and transient thermal measurements of green roof substrates. Building and Environment (2016) 131: 123-131.

12. Wong NH, Chen $\mathrm{Y}$, Ong CL, Sia A. Investigation of thermal benefits of rooftop garden in the tropical environment. Building and Environment (2003), 38, 261-270.

13. Sun T, Bou-Zeid E, Wang Z, Zerba E, Ni G. Hydrometeorological determinants of green roof performance via a vertically-resolved model for heat and water transport. Building and Environment (2013), 60: 211-224.

14. Robinson PJ, on the definition of a heat wave. J Applied Meteorology (2001) 40:762-775.

15. Anderson GB, Bell ML, Peng RD. Methods to calculate the $\mathrm{HI}$ as an exposure metric in environmental health research, Environmental Health Perspectives, Environmental Health Perspectives (2013) 10, 11111119. 
16. Steadman RG. The assessment of sultriness. Part I: A temperature-humidity index based on human physiology and clothing science, Journal Applied Meteorology 18, (1979a) 861-873.

17. Steadman RG. The assessment of sultriness. Part II: Effects of wind, extra radiation and barometric pressure on apparent temperature, Journal Applied Meteorology 18 pp. (1979b) 874-885.

18. Steadman RG. A universal scale of apparent temperature, Journal of Climate Applied Meteorology' 23, (1984) 1674-1687

19. Niachou A, Papakonstantinou K, Santamouris M, Tsangrassoulis A, Mihalakakou G. Analysis of the green roof thermal properties and investigation of its energy performance. Energy and Buildings, 33, (2001) 719-729.

20. Parizotto S, Lamberts R. Investigation of green roof thermal performance in temperate climate: a case study of an experimental building in Florianópolis city Southern Brazil, Energy and Buildings, 43 (2011), pp. $1712-1722$

21. Chen $Q$, et al. An experimental evaluation of the living wall system in hot humid climate Energy and Buildings, 61 (2013), pp. 298-307

22. Pandey S, Hindoliya DA, Mod R. Experimental investigation on green roofs over buildings, International Journal of Low-Carbon Technologies 8 (2013)37-42

23. Wong NH, Tan PY, Chen Y. Study of thermal performance of extensive rooftop greenery systems in the tropical climate, Building and Environment 42 (2007) 25-54.

24. Djedjig R, Bozonnet E, Belarbi R, Analysis of thermal effects of vegetated envelopes: Integration of a validated model in a building energy simulation program', Energy and Buildings, 86 (2015) 93-103.

25. Wong NH, Cheong DKW, Yan H, Soh J, Ong CL, Sia A. The effects of rooftop garden on energy consumption of a commercial building in Singapore, Energy and Buildings 35, (2003) 353-364.

26. Lazzarin RM, Castellotti F, Busato F. Experimental measurements and numerical modelling of a green roof. Energy and Buildings, 37, (2005) 1260-1267.

27. Kumar R, Kaushik SC. Performance evaluation of green roof and shading for thermal protection of buildings. Building and Environment (2005), 40: 1505-1511.

28. Ould-Bouthikine S, Belarbi R, Jaffal I, Trabelsi A. Assessment of green roof thermal behaviour: a coupled heat and mass transfer model. Building and Environment (2011), 46: 2624-2631.

29. Ayata T, Tabares-Velasco PC, Srebric J. An investigation of sensible heat fluxes at a green roof in a laboratory setup. Building and Environment (2011), 46: 1851-1861.

30. Zhao M, Tabares-Velasco PC, Srebric J, Komarneni S, Berghage R. Effects of plant and substrate selection on thermal performance of green roofs during the summer. Building and Environment (2014), 78: $199-211$

31. Cascone S, Catania F, Gagliano A, Sciuto G. A comprehensive study on green roof performance for retrofitting existing buildings. Building and Environment, (2018) 136: 227-239.

32. Alcazar S, Bass B. Energy performance of green roofs in a multi storey residential building in Madrid, in Greening Rooftops for Sustainable Communities; Green Roofs for Healthy Cities, Washington, DC, USA, (2005)

33. Castleton H. Green roofs: building energy savings and the potential for retrofit, Energy and Buildings 42, (2010) 1582-1591.

34. Lin B-S, Yu C-C, Su A-T, Lin Y-J. Impact of climatic conditions on the thermal effectiveness of an extensive green roof. Building and Environment (2013) 67: 26-33. 
35. Ouldboukhitine SE, Belarbi R, Djedjig R. Characterization of green roof components: measurements of thermal and hydrological properties, Building and Environment (2012) 56: 78-85.

36. Sun T, Bou-Zeid E, Ni G-H. To irrigate or not to irrigate: analysis of green roof performance via a vertically-resolved hygrothermal model Building and Environment (2014) 73: 127-37.

37. Bevilacqua P, Coma J, Pérez G, Chocarro C, Juárez A, Solé C, De Simone M, Cabeza LF. Plant cover and floristic composition effect on thermal behaviour of extensive green roofs. Building and Environment (2015) 92: 305-316.

38. Mertz O, Halsnaes K, Olesen JE and Rasmussen K. Adaptation to climate change in developing countries, Environmental management 45, (2009) 743-752.

39. He Y, Yu H, Ozaki A, Dong N, Zheng S. Long-term thermal performance evaluation of green roof system based on two new indexes: A case study in Shanghai area. Building and Environment. (2017) 120: 13-28.

40. Blanusa T, Vaz Monteiro MM, Fantozzi F, Vysini E, Li Y, Cameron RWF. Alternatives to Sedum on green roofs: Can broad leaf perennial plants offer better 'cooling service? Building and Environment. (2013) 59: $99-106$

41. Lin YJ, Lin HT. Thermal performance of different planting substrates and irrigation frequencies in extensive tropical rooftop greeneries. Build. Environ. 46 (2011) 345-355.

42. Collins S, Kuoppamaki K, Kotz DJ. Xiaoshu Lü. Thermal behavior of green roofs under Nordic winter conditions, (2017) 22: 206-214

43. La Roche P, Berardi U. Comfort and energy savings with active green roofs, Building and Environment. (2014) 82: 492-504.

44. Black CC, Osmond CB. Crassulacean acid metabolism photosynthesis: working the night shift. Photosynthesis Research (2003): 76 329-41.

45. Wilkinson SJ, Castiglia Feitosa R. Retrofitting Housing with Lightweight Green Roof Technology in Sydney, Australia, and Rio de Janeiro, Brazil, Sustainability 7, (2015) 1081-1098.

46. Designing Building Wiki. Albedo in the built environment. https://www.designingbuildings.co.uk/wiki/Home (2018) (acessed 10 April 2018)

47. INMET. Precipitação Acumulada Mensal e Anual (mm) 1981-2010. Brazilian National Institute of Meteorology http://www.inmet.gov.br/portal/index.php?r=clima/normaisClimatologicas (2018) (acessed 05 April 2018)

48. BOM. Climate Data Online. Bureau of Meteorology - Australian Government. http://www.bom.gov.au/climate/data/ (2018) (acessed 05 April 2018)

49. NWS (National Weather Service), Meteorological Conversions and Calculations: HI Calculator. Available: http://www.hpc.ncep.noaa.gov/html/heatindex. html [accessed 25 January 2017].

50. Patore L, Corrao R, Heiselberg PK. The effects of vegetation on indoor thermal comfort: The application of a multi-scale simulation methodology on a residential neighborhood renovation case study, Energy and Buidings. (2017) 146:1-11.

51. Fioretti R, Palla A, Lanza LG, Principi P. Green roof energy and water related performance in the Mediterranean climate, Building and Environment. (2010) 45:1890-1904. 